\title{
Relations Among Locus of Control, Religiosity, and Resiliency in Collegiate Football Players
}

\author{
Chazz P. Slatinsky $^{1}$ (D) Gene L. Farren ${ }^{1}$ (D) . Michelle Bartlett ${ }^{1}$ (D) Vanessa Fiaud $^{1}$ (D) . \\ Rick Haasl $^{1}$ (iD
}

Accepted: 22 November 2021 / Published online: 8 January 2022

This is a U.S. government work and not under copyright protection in the U.S.; foreign copyright protection may apply 2021

\begin{abstract}
Resiliency in athletes is related to effective coping strategies. Expectedly, during the COVID-19 pandemic, this attribute was highlighted in collegiate football players. To date, the relations among locus of control (LOC), strength of religious beliefs (i.e., religiosity), and resiliency in collegiate football players have not been explored in the literature. Exploring the relation of LOC and religious beliefs to resiliency may shed light on avenues to foster resiliency in football players, which in turn can determine players' behaviors, performance, and actions during adverse times. The purpose of this study was to gain a more in-depth understanding of the relations among LOC, religiosity, and resiliency in NCAA Division II football players at a public university located in the southwestern United States. A structured online survey containing the Rotter's Locus of Control Scale (Rotter in Psychological Monographs: General and Applied, 80(1), 1-28, 1966), the Santa Clara Strength of Religious Faith Questionnaire (Plante \& Boccaccini in Pastoral Psychology, 45(6), 429-437, 1997), and the Conner Davidson Resilience Scale (Connor \& Davidson in Depression and Anxiety, 18(2), 76-82, 2003) was completed by 91 Division II football players. Statistically significant correlations were found between LOC and resiliency $(r=$ $-.42)$ as well as religiosity and resiliency $(r=.26)$. Regression analysis indicated, on average, that football players with greater internal LOC and higher strength of religious beliefs had a higher level of resiliency than players with higher external LOC and lower strength of religious beliefs.
\end{abstract}

Keywords Athletes $\cdot$ National collegiate athletic association (NCAA) $\cdot$ Religion $\cdot$ Faith

Throughout history, many individuals have worshipped gods or goddesses such as Zeus, Osiris, or Thor (Jordan, 1993). But the worship of such gods is not just a memory from times past. This fundamental idea (i.e., belief in a higher power) continues to thrive in today's world (Sherwood, 2018). Religious believers across the world tend to follow higher powers or supernatural agents. For instance, Muslims follow Allah, Christians follow God

Gene L. Farren

gfarren@wtamu.edu

1 Department of Sports and Exercise Sciences, West Texas A\&M University, Canyon, TX, USA 
or the Father, and Hindus follow Brahman (Vail et al., 2012). Supernatural is defined as "1. of or relating to an order of existence beyond the visible observable universe, especially of or relating to God or a god, demigod, spirit, or devil; 2a. departing from what is usual or normal especially so as to appear to transcend the laws of nature" (Merriam-Webster, n.d.).

Recent research has indicated religious beliefs can foster positive effects on athletes' mental health and may contribute to better performance-related outcomes (Noh \& Shahdan, 2020). Storch et al. (2001) concluded that religion is often a core value of athletes, which may empower these individuals to pray, to foster their inner strength, or to receive comfort as a means of coping during adverse times. Participation in intercollegiate athletics is associated with various stressors (e.g., injury, competition for playing time), which is why many athletes may turn towards religious and spiritual beliefs for guidance in coping with uncertainty (Storch et al., 2001).

Noh and Shahdan (2020) suggest religion plays an important role for many athletes in a variety of ways (e.g., coping strategies, well-being, and anxiety reduction). Further, Czech and Bullet (2007) found that Christian athletes strongly support the use of prayer before and after competition. Hoffman (1992) claimed the relationship between sport and religion has been of interest to researchers, who have realized the importance of religion in many athletes' lives. Studies, such as those of Jeroh (2012) and Jona and Okou (2013), explain that many athletes and coaches use religion as a psychological support tool to help them face the stressors of life and challenges in competition. As previously noted, religious beliefs are also often significantly positively correlated with effective coping in stressful situations. Resiliency is defined as the capacity and dynamic process of adaptively overcoming stress and adversity while maintaining normal psychological and physical functioning (Wu et al., 2013). Thus, a person's resiliency may refer to their ability to overcome troubled times or their effectiveness in coping with adversity. Because previous research has indicated stress-coping ability is positively related to religiosity (Eryilmaz, 2015) and effective coping skills are positively related to enhanced performance (Kurimay et al., 2017), gaining a better understanding of the relationship between resiliency and religiosity is warranted. This knowledge may provide effective avenues to enhance performance.

Eryilmaz (2015) found that, on average, students who participated in religious activities had greater subjective well-being and felt this practice helped them manage stress. In addition, participation in religious activities was significantly related to mental control $(r=.43$, $p<.05)$. Locus of control (LOC) is defined as a person's belief about the degree of control they, as opposed to external forces, have on outcomes in their life (Rotter, 1966). Specifically, individuals who have more of an internal LOC believe they are in control of their outcomes and influence their results. In contrast, individuals who have greater external LOC believe their outcomes are caused by something that cannot be influenced by them directly and that the results are out of their control (Burns et al., 2013). Further, Rotter (1966) states that persons with more internal LOC believe their behaviors or accomplishments come from within themselves, whereas a person with more external LOC believes that factors such as luck, chance, fate, or a powerful other allow them to achieve their goals or adopt specific behaviors.

This understanding of LOC suggests that a powerful other, which is ultimately outside of one's own ability, could be considered analogous with a supernatural agent. This understanding also suggests that a person with greater religiosity would have greater external LOC. Koenig (2012) defined religiosity as an organized system of beliefs, practices, and symbols designed (a) to facilitate closeness to the transcendent other, higher power, or ultimate truth and (b) to bring about an understanding of an individual's 
relationship and responsibility to others living together in community. Again, the higher power definition may suggest that individuals with stronger beliefs would generally feel more externally controlled. However, some studies have found that stronger religious beliefs foster a greater feeling of personal control (Gall et al., 2000). Storch et al. (2001) found that religiosity has an effect on athletes' performances during competition or hardships, but its relationship with LOC has yet to be explored. According to Rotter (1966), LOC is an essential component of an individual's personality and one of many components that influence a person's life. Timmins and Martin (2019) state that exploring the complex relationship between LOC and religious beliefs is warranted; however, as previously noted, the research provides conflicting theories on how LOC and essential components of religiosity might relate (Burns et al., 2013; Gall et al., 2000).

Overall, there is a lack of understanding of the relations among locus of control (LOC), religiosity, and resiliency in individuals (Munoz et al., 2017). The relations among LOC, religiosity, and resiliency levels have yet to be explored in collegiate athletes. Further, specifically exploring the predictive relationships that LOC and religiosity hold regarding the resiliency of collegiate athletes may provide an avenue that practitioners (e.g., sports chaplains, coaches, and athletic trainers) can pursue to possibly enhance an athlete's performance. Burns et al. (2013) has shown that the concept of LOC in collegiate athletes can be beneficial when understood and recognized by an athlete's support services. Given that one of the prime motivations for this research is to provide knowledge to practitioners for a better understanding of the mitigating relations of these factors (i.e., LOC, religiosity, and resiliency), the purpose of this research study was to (a) examine the relations among LOC, religiosity, and resiliency in NCAA Division II football players, (b) examine the predictive relationships LOC and religiosity held on resiliency in NCAA Division II football players, and (c) explore whether religiosity moderates the relationship between LOC and resiliency.

Based on the literature reviewed, we first hypothesized that LOC (i.e., greater internal LOC) and strength of religious beliefs (i.e., religiosity) would both have a significant positive relationship with resiliency in NCAA Division II football players. Second, we hypothesized that LOC (i.e., greater external LOC) would have a significant positive relationship with religiosity in NCAA Division II football players. Third, we hypothesized that religiosity and LOC would both hold a significant predictive relationship with resiliency and that religiosity would moderate the relationship between LOC and resiliency in the sample of collegiate athletes.

\section{Method}

\section{Participants}

Participants were 91 male collegiate football players from a Division II public university located in the southwestern United States. Of the participants, 19 were freshmen (21\%), 29 were sophomores (32\%), 26 were juniors (29\%), 13 were seniors (14\%), 3 were graduate students (3\%), and 1 was other (1\%). In addition, 74 identified as Christian (81.3\%), 1 as Muslim (1.1\%), 1 as atheist (1.1\%), and 15 as other (16.5\%). An a priori power analysis indicated a minimum of 68 participants were needed to have $80 \%$ power for detecting a small effect with an alpha of .05 for statistical significance. 


\section{Measures}

Demographics assessed were university classification (e.g., freshman) and religious preference identity. University classification was used to compare the sample with the football team's population.

LOC was assessed using Rotter's Locus of Control Scale (1966), which is a 29-item dichotomous forced-choice test (i.e., internal or external control) that includes six filler items to obscure the purpose of the test. The pertinent 23 items of the test are samples of attitudes in a wide variety of different situations; the participants are asked to select the statement they agreed with the most. One point is scored when the participants select the external LOC statement, and zero points are scored when the participants select the internal LOC statement. Therefore, scores can range from 0-23, and the higher the participants' score the more they feel controlled externally (Rotter, 1966). Previous research (Lange td \{border: 1px solid \#ccc;\}br \{mso-data-placement:same-cell;\}\& Tiggemann, 1981) found scores for this measure to have acceptable internal consistency (Spearman-Brown $=.65$ to .79). Scores in the present study were consistent with previous research (Spearman-Brown $=.68)$.

The 10-item Santa Clara Strength of Religious Faith Questionnaire (Plante \& Boccaccini, 1997) was used to assess the participants' strength of religious beliefs. Participants were asked to indicate the extent to which they agreed, on a 4-point scale ranging from $1=$ strongly disagree to 4 = strongly agree, with statements evaluating religious engagement. Items were summed to obtain a total score for the strength of religious beliefs (SR), with higher scores indicating greater strength of religious beliefs. Consistent with previous research (Plante, 2010), participants' scores demonstrated high internal consistency $(\alpha=.94)$.

The 10-item Conner-Davidson Resilience Scale (Connor \& Davidson, 2003) was used to assess participants' resiliency. Participants were asked to indicate the extent they felt the provided statements applied to them on a 5-point scale ranging from $0=$ not true at all to $4=$ true nearly all the time. Items were summed to derive a composite score for resiliency (CDR), with higher scores indicating greater resiliency. Consistent with previous research (Gonzalez et al., 2016), participants' scores demonstrated high internal consistency $(\alpha=$ $.83)$.

\section{Statistical analysis}

Data were collected using Qualtrics XM (Qualtrics, Provo, UT, USA) and then systematically imported into SPSS ${ }^{\circledR} 24.0$ (IBM Corporation, Armonk, NY, USA) for statistical analyses. Statistical significance was set at $\alpha<.05$. G*Power Version 3.1.9.6 (Faul et al., 2009), which was used to perform an a priori power analysis. After the data were imported, missing values and reliability were explored and the studied composite factors were computed and then assessed for outliers and normality of the distributions. No data was missing. A two-step transformation (Templeton, 2011) was performed to correct the skewness of the SR variable. Correlation analyses were conducted to examine the relations among the variables. Lastly, a hierarchical regression analysis (i.e., moderation analysis) was conducted to assess the predictive relations of the independent variables (i.e., SR and LOC) and to test whether SR influenced the relation between LOC and CDR. This was conducted by computing an interaction term (SR*LOC) and entering SR*LOC in step 2. 
Table 1 Correlation Coefficients for the Strength of Religious Beliefs (SR), Locus of Control (LOC), and Resiliency (CDR) Factors

\begin{tabular}{llll}
\hline Factor & SR & LOC & CDR \\
\hline SR & - & -.139 & $.318^{* *}$ \\
LOC & & - & $-.416^{* *}$ \\
CDR & & & - \\
\hline$* * p<.01$ & & &
\end{tabular}

\section{Results}

Descriptive statistics revealed participants' $(N=91)$ mean SR was $30.64 \pm 6.13$, mean LOC was $10.80 \pm 3.36$, and mean CDR was $30.79 \pm 5.0$. Based on previous research (Storch et al., 2004; Strawser et al., 2004), participants, on average, had elevated SR scores, signifying strong religious beliefs in this sample. In addition, these results indicated that participants rated themselves, on average, more internally controlled, and they had CDR scores consistent with previous research (Gonzalez et al., 2016). Table 1 presents the correlation coefficients of the studied factors. A summary of the moderation analysis is presented in Table 2 . The moderation analysis yielded a statistically significant result for step $1, R^{2}=.24, F(2,88)=14.05, p<.01$; however, step 2 yielded a non-statistically significant result, $\Delta R^{2}=.01, F(1,87)=0.96, p=.329$. These results indicated that although both $\mathrm{SR}$ and LOC were statistically significant predictors of CDR, no significant interaction or moderation existed.

\section{Discussion}

The main purpose of this study was to examine the relations among LOC, religiosity, and resiliency levels in football players from a Division II university located in the southwestern United States. Our results indicated, on average, that athletes who had more internal LOC and higher religiosity also demonstrated higher levels of resiliency than athletes who had higher external LOC and lower strength in religious beliefs. These findings supported the first hypothesis that LOC (i.e., greater internal LOC belief) and religiosity would have a significant positive relationship with resiliency in football players. Although this study was the first to collectively explore the relations

Table 2 Summary of the Moderation Analysis

\begin{tabular}{lrrrrrr}
\hline & \multicolumn{1}{c}{$B$} & \multicolumn{1}{l}{$S E$} & $\beta$ & \multicolumn{1}{l}{$t$} & $R^{2}$ & \multicolumn{1}{l}{$r_{s}$} \\
\hline Step 1 & & & & & .24 & \\
(Constant) & 30.12 & 3.03 & & $9.94^{* *}$ & & \\
SR & 0.22 & 0.08 & .27 & $2.83 * *$ & & \\
LOC & -0.56 & 0.14 & -.38 & $-4.04 * *$ & & \\
Step 2 & & & & & .25 & \\
(Constant) & 37.80 & 8.39 & & $4.50^{* *}$ & & \\
SR & -0.02 & 0.26 & -.03 & -0.08 & & $.64 * *$ \\
LOC & -1.27 & 0.74 & -.86 & -1.73 & & $-.83^{* *}$ \\
SR*LOC & 0.02 & 0.02 & .53 & 0.98 & & $-.37^{* *}$ \\
\hline
\end{tabular}

$* * p<.01 ; N=91$ 
among these factors, this result was consistent with previous literature (Eryilmaz, 2015; Gall et al., 2000; Rajan et al., 2018).

Although the second hypothesis that LOC (i.e., greater external LOC) would significantly relate with religiosity in football players was not supported, this finding was consistent with previous research (Friedberg \& Friedberg, 1985). Rajan et al. (2018) revealed that a person who is more internally controlled has greater resiliency when compared to a person who is functioning from an external LOC. As previously stated, a person with more internal LOC believes that their behaviors or accomplishments come from within themselves, whereas a person with more external LOC believes that factors such as luck, chance, fate, or a powerful other allow them to achieve a particular accomplishment or behavior (Rotter, 1966). Given that LOC is deemed a prime component of personality (Rotter, 1966), we investigated how LOC is correlated with religiosity and resiliency levels. Sherwood (2018) found that $84 \%$ of the world's population identifies themselves as a part of a religious group. This significant percentage raises questions on how religiosity is correlated with the LOC and resiliency levels of individuals and the significance of this relationship. Knowing that resiliency is an important factor in an individual's ability to overcome troubled times, our findings suggest that strengthening religious beliefs in athletes also may foster greater resiliency.

Whereas our findings did support the first part of the third hypothesis that both religiosity and LOC would have a significant predictive relationship with resiliency, they did not support the second part that religiosity would moderate the relationship between LOC and resiliency. This relationship may, however, be found in other samples_-perhaps in different sports and/or geographical locations. Due to the small amount of extant research on this relationship, additional research on this topic is warranted. By reaching out to a greater number of athletes, researchers may identify whether or not this trend exists in a larger and more diversified sample. Again, to our knowledge, this was the first study to examine the influence religiosity had on the relationship between LOC and resiliency in athletes. Therefore, this study expands the existing knowledge regarding these relations and should support practitioners (e.g., sports chaplains, coaches, athletic trainers) who promote religiosity as a way to enhance athletic performance. Overall, the present findings support the belief that while a higher power may grant the athlete ability, physical gifts, and drive, as well as provide them with someone to rely on during times of struggle, it is still ultimately up to the athlete to use these attributes.

The findings of this study should be considered in light of the following limitations. First, given the geographical location of this sample and the elevated SR scores, the generalizability of these results may be limited to similar samples. To determine whether findings remain consistent and to increase generalizability, further research on these relations should examine samples from different geographical areas and athletes participating in other sports, including but not limited to individuals in different universities, countries, and learning settings. Second, cross-sectional research does not allow researchers to establish causality. Therefore, to truly investigate whether strengthening religious beliefs can cause a change in resiliency over time, future researchers could utilize a longitudinal research design. Third, though self-report measures allow for easier data collection, self-reported data is subject to biases (e.g., social desirability), which may have underestimated and overestimated the athletes' response (Watkinson et al. 2010). Lastly, given that this survey was disseminated online, if the athlete did not understand concepts or questions within the survey, researchers could not provide necessary clarification. 
Acknowledgments The researchers would like to thank all the athletes who participated in this study and the staff and coaches who helped make this study possible.

Author contributions All authors whose names appear on the submission (1) made substantial contributions to the conception or design of the work; or the acquisition, analysis, or interpretation of data; or the creation of new software used in the work; (2) drafted the work or revised it critically for important intellectual content; (3) approved the version to be published; and (4) agreed to be accountable for all aspects of the work in ensuring that questions related to the accuracy or integrity of any part of the work are appropriately investigated and resolved.

Raw data is available upon request

\section{Declarations}

Ethics approval Ethical approval for this study was obtained from the Institutional Review Board. IRB: 2020.12.001; approved: December 15, 2020; expiration date: December 14, 2021.

Consent to participate The following statement was provided to all participants before beginning the survey. "I understand that I may want to participate in this study to help the researcher obtain more information. I understand that though this study may not benefit me directly, the evidence gained may provide the investigator insight into how these factors relate and interact. Hopefully, the knowledge gained from this study may benefit health and coaching professionals. I further understand that I may not want to participate due to personal reasons or desire not to participate."

\section{References}

Burns, G. N., Jasinski, D., Dunn, S., \& Fletcher, D. (2013). Academic support services and career decisionmaking self-efficacy in student athletes. Career Development Quarterly, 61(2), 161-167. https://doi. org/10.1002/j.2161-0045.2013.00044.x

Connor, K. M., \& Davidson, J. R. T. (2003). Development of a new resilience scale: The Connor-Davidson Resilience scale (CD-RISC). Depression and Anxiety, 18(2), 76-82. https://doi.org/10.1002/da.10113

Czech, D. R., \& Bullet, E. (2007). An exploratory description of Christian athletes' perceptions of prayer in sport: A mixed methodological pilot study. International Journal of Sports Science \& Coaching, 2(1), 49-56. https://doi.org/10.1260/174795407780367212

Eryilmaz, A. (2015). Investigation of the relations between religious activities and subjective well-being of high school students. Educational Sciences: Theory \& Practice, 15(2), 433-444. https://doi.org/10. 12738/estp.2015.2.2327.

Faul, F., Erdfelder, E., Buchner, A., \& Lang, A.-G. (2009). Statistical power analyses using G*Power 3.1: Tests for correlation and regression analyses. Behavior Research Methods, 41, 1149-1160. https://doi. org/10.3758/BRM.41.4.1149

Friedberg, B. A., \& Friedberg, R. D. (1985). Locus of control and religiosity in college students. Psychological Reports, 56(3), 757-758.

Gall, T. L., Miguez de Renart, R. M., \& Boonstra, B. (2000). Religious resources in long-term adjustment to breast cancer. Journal of Psychosocial Oncology, 18(2), 21-37. https://doi.org/10.1300/J077v18n02_ 02

Gonzalez, S. P., Moore, E. W. G., Newton, M., \& Galli, N. A. (2016). Validity and reliability of the ConnorDavidson Resilience Scale (CD-RISC) in competitive sport. Psychology of Sport and Exercise, 23, 31-39. https://doi.org/10.1016/j.psychsport.2015.10.005

Hoffman, S. J. (1992). Sports and Religion. Human Kinetics.

Jeroh, E. J. (2012). The multi-dimensional relationship between religion and sport. Journal of Physical Education and Sport Management, 3(1), 1-7. https://doi.org/10.5897/JPESM.9000021

Jona, I. N., \& Okou, F. T. (2013). Sports and religion. Asian Journal of Management Sciences and Education, 2(1), 46-54.

Jordan, M. (1993). Encyclopedia of Gods: Over 2500 deities of the world. Facts in File.

Koenig, H. G. (2012). Religion, spirituality, and health: The research and clinical implications. ISRN Psychiatry, 2012, 1-33. https://doi.org/10.5402/2012/278730

Kurimay, D., Pope-Rhodius, A., \& Kondric, M. (2017). The relationship between stress and coping in table tennis. Journal of Human Kinetics, 55(1), 75-81. https://doi.org/10.1515/hukin-2017-0007 
Lange, R. V., \& Tiggemann, M. (1981). Dimensionality and reliability of the Rotter I-E Locus of Control Scale. Journal of Personality Assessment, 45(4), 398-406. https://doi.org/10.1207/s15327752jpa4504_9

Merriam-Webster. (n.d.). Merriam-Webster.com dictionary. https://www.merriam-webster.com/. Accessed 18 Sep 2021.

Munoz, R. T., Brady, S., \& Brown, V. (2017). The psychology of resilience: A model of the relationship of locus of control to hope among survivors of intimate partner violence. Traumatology, 23(1), 102-111. https://doi.org/10.1037/trm0000102

Noh, Y. E., \& Shahdan, S. (2020). A systematic review of religion/spirituality and sport: A psychological perspective. Psychology of Sport and Exercise, 46, Article 101603. https://doi.org/10.1016/j.psychsport. 2019.101603

Plante, T. G. (2010). The Santa Clara Strength of Religious Faith Questionnaire: Assessing faith engagement in a brief and nondenominational manner. Religions, 1(1), 3-8. https://doi.org/10.3390/rel1010003

Plante, T. G., \& Boccaccini, M. (1997). Reliability and validity of the Santa Clara Strength of Religious Faith Questionnaire. Pastoral Psychology, 45(6), 429-437. https://doi.org/10.1007/BF02310643

Rajan, A. M., Srikrishna, G., \& Romate, J. (2018). Resilience and locus of control of parents having a child with intellectual disability. Journal of Developmental and Physical Disabilities, 30(3), 297-306. https://doi.org/10.1007/s10882-018-9586-0

Rotter, J. B. (1966). Generalized expectancies for internal versus external control of reinforcement. Psychological Monographs: General and Applied, 80(1), 1-28.

Sherwood, H. (2018). Religion: Why faith is becoming more and more popular. The Guardian. https://www. theguardian.com/news/2018/aug/27/religion-why-is-faith-growing-and-what-happens-next.

Storch, E. A., Kolsky, A. R., Silvestri, S. M., \& Storch, J. B. (2001). Religiosity of elite college athletes. The Sport Psychologist, 15, 346-351.

Storch, E. A., Roberti, J. W., Bravata, E. A., \& Storch, J. B. (2004). Strength of religious faith: A comparison of intercollegiate athletes and non-athletes. Pastoral Psychology, 52(6), 485-489. https://doi.org/ 10.1023/b:pasp.0000031527.02433.5b

Strawser, M. S., Storch, E. A., Geffken, G. R., Killiany, E. M., \& Baumeister, A. L. (2004). Religious faith and substance problems in undergraduate college students: A replication. Pastoral Psychology, 53(2), 183-188. https://doi.org/10.1023/b:pasp.0000046829.61450.4c

Templeton, G. F. (2011). A two-step approach for transforming continuous variables to normal: Implications and recommendations for IS research. Communications of the Association for Information Systems, 28, Article 4.

Timmins, F., \& Martin, C. (2019). Spirituality and locus of control—A rapid literature review. Spirituality in Clinical Practice, 6(2), 83-99.

Vail, K. E., Arndt, J., \& Abdollahi, A. (2012). Exploring the existential function of religion and supernatural agent beliefs among Christians, Muslims, atheists, and agnostics. Personality and Social Psychology Bulletin, 38(10), 1288-1300. https://doi.org/10.1177/0146167212449361

Watkinson, C., van Sluijs, E. M. F., Sutton, S., Hardeman, W., Corder, K., \& Griffin, S. J. (2010). Overestimation of physical activity level is associated with lower BMI: A cross-sectional analysis. International Journal of Behavioral Nutrition and Physical Activity, 7, 1-9. https://doi.org/10.1186/ 1479-5868-7-68

Wu, G., Feder, A., Cohen, H., Kim, J. J., Calderon, S., Charney, D. S., \& Mathé, A. A. (2013). Understanding resilience. Frontiers in Behavioral Neuroscience, 7, 1-15. https://doi.org/10.3389/fnbeh.2013. 00010

Publisher's Note Springer Nature remains neutral with regard to jurisdictional claims in published maps and institutional affiliations. 